\title{
MORPHOMETRIC STUDY OF THE TRACHEA IN HUMAN FETUSES
}

\author{
Catarine C. Matos ${ }^{1}$, Rodrigo R. Almeida ', José A. Aragão ', Erasmo Almeida- \\ Junior ${ }^{1}$, Francisco P. Reis *1. \\ ${ }^{1}$ Department of Medicine, Tiradentes University, Aracaju-SE, 49032-490, Brazil.
}

\section{ABSTRACT}

Background: The advancement of perinatal health care combined with the advancement of visual techniques that have been implemented allows surgeons and anesthesiologists to perform airway management and detect, monitor and surgically treat life-threatening tracheobronchial tree abnormalities. In this context it is very important to know the anatomy of the trachea in fetuses.

Results: The total length of trachea had significant progressive growth with the gestational age, highlighted differences the 20-24 week age group, 29-32 week age group and 33-38 week age group. Similar occurrence was found in these same groups with respect to pre-bifurcation length. Regarding to proximal transverse external diameter and distal transverse external diameter it was observed significant differences between age groups from 20 to 24 weeks, 25 to 28 weeks and 33 to 38 weeks. As the influence of gestational age and sex or both of the measures studied tracheal significant differences occurred only in relation to gestational age. This did not occur with respect to $B L$ and number of cartilage rings.

Conclusions: It is possible that the current findings are a contribution in the child's anatomy course and lead the clinical and surgical interest of that act, especially in intensive care units of newly born, as well as in surgery of children's airways.

KEY WORDS: Airway, Morphometry, Gestational age, Gender.

Corresponding Author: Francisco P. Reis, Department of Medicine, Tiradentes University, Aracaju-SE, 49032-490, Brazil. E-Mail: franciscopradoreis@gmail.com

Access this Article online

Quick Response code

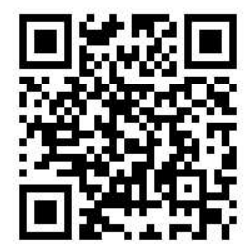

DOI: $10.16965 /$ ijar.2020.205
Journal Information

International Journal of Anatomy and Research

RG Journal ISSN (E) 2321-4287 | ISSN (P) 2321-8967

Impact: 0.21* https://www.ijmhr.org/ijar.htm

DOI-Prefix: https://dx.doi.org/10.16965/ijar

\section{Article Information}

Received: 12 Aug 2020

Peer Review: 12 Aug 2020

Revised: None
Accepted: 26 Aug 2020

Published (O): 10 Sep 2020

Published (P): 10 Sep 2020

\section{INTRODUCTION}

The trachea, considered as the continuation of the larynx, is an elastic tube formed by horseshoe-shaped cartilage and subsequently by a membrane fibromuscular internally lined with mucosa, located between the lower border of the cricoid cartilage to the bifurcation of the bronchi. It is lined with a mucous tunic formed by ciliated pseudostratified cylindrical epithelium and longitudinal elastic fibers, as well as a submucosal layer with glands [1,2].

In adults, its length varies from 9 to $15 \mathrm{~cm}$ and its diameter from 1.5 to $2.0 \mathrm{~cm}$. The trachea is divided into two portions, one cervical and one thoracic. In the newborn, its length is approxima- -tely $4 \mathrm{~cm}$ and increases by about $50 \%$ until puberty and triples in adulthood. The average diameter increases from about $6 \mathrm{~mm}$ at birth to up to $20 \mathrm{~mm}$ in adulthood [1,2]. The anterolateral part consists of incomplete cartilaginous rings and the posterior one by a flat muscular wall. It descends from the larynx at the level of the sixth cervical vertebra to the upper edge of the fifth thoracic vertebra, where it divides into the right and left main (pulmonary) bronchi. The bifurcation level may change depending on age: at birth, it is at T3 or T4 level; at 4 years of age, at T5; and from 12 years of age to adulthood, between $\mathrm{T} 5$ and T6. This anatomical detail is very important when performing external evaluation of the carina during an intubation, 
as proper endotracheal tube position is essential for optimal ventilation $[1,2]$.

The first rudiments of the 16 to 20 cartilages appear as a crescent shape around the eighth week of pregnancy ( 28 to $30 \mathrm{~mm}$ embryo), in the thickness of the condensed mesenchyme surrounding the trachea. The number of tracheal rings will be the same until the end of the individual's life, being arranged regularly, with the function of keeping the airflow passage open $[2,3]$. This period coincides with the considered fetal period, which lasts from the ninth week until birth and is characterized by maturation of tissues and organs, and rapid body growth [4].

The dimensions and shape of the trachea can be modified due to several variables: intraluminal pressure, respiratory phase and position (erect, supine, prone, flexion, extension or rotation). Changes are also seen with age. For example, after puberty there is an increase in tracheal length, mainly as a result of an increase in annular ligament width [2].

Quantitative data on anatomical aspects during tracheal growth in human fetuses have remained a recurring theme in the literature. In general, our knowledge of the functional and structural features of the entire tracheobronchial tree is limited, largely because of problems that restrict the study of the respiratory system during life. The maximum available data on tracheal size and shape were obtained from cadavers, either by direct tracheal mold measurement or by dilators $[5,6]$.

The advancement of perinatal health care combined with the advancement of visual techniques that have been implemented allows surgeons and anesthesiologists to perform airway management and detect, monitor and surgically treat life-threatening tracheobronchial tree abnormalities. The systematic use of placental oxygenation in ex-utero intrapartum treatment (EXIT) has resulted in the survival of many healthy children [6-10].

In general, attempted fetal intubation or airway interventions are performed from the gestational age of 24 weeks [4,11].

Information about the anatomical knowledge of the trachea, especially its dimensions, is considered important for any specialty that works in the airways, especially physiotherapists, otolaryngologists, speech therapists, anesthetists and emergentists, among others. Anatomical knowledge of the airways is essential to the success of tracheal intubation, a common procedure in emergency units, intensive care and operating rooms. Access to the airways without prior anatomical knowledge can have serious consequences. Anatomical study of the airways may also be useful in research on pulmonary physiology, in anthropometry and in various tracheobronchial tree procedures $[12,13]$.

Currently, the choice of an appropriately sized endotracheal tube (ETT) for use in premature newborns has been limited, as this choice always seems to be based on clinical reports and industry recommendations. From the clinical point of view, knowledge of the anatomy of the larynx as well as the trachea becomes useful. This will allow healthcare professionals to select the most appropriate size of endotracheal tube, which will consequently entail the airway safety of the premature infants who may need intrauterine airway interventions $[12,14]$.

The literature reports some types of lesions related to the wrong choice of endotracheal tube size. These studies demonstrated that the lesion can occur on two levels: at the posterior part of the gothic plan, with risk of vocal process necrosis or cricoarytenoid ankylosis, and at the subglottic level, with risk of cricoid necrosis and subglottic stenosis. Regarding the etiology, two types of lesions were described: mucosal and ischemic lesions. Multiple causes seem to be in the genesis of these lesions, but most authors agree that the main determining factor is excessive tube size [15]. Also, poor placement of the endotracheal tube within the airway can lead to serious complications such as endobronchial intubation, vocal cord paralysis, and accidental extubation [16-18]. The incidence of tracheal post-intubation stenosis was decreased with recognition of its etiology; however, it remains the most common indication for tracheal surgery $[16,19,20]$.

Treatment of pediatric laryngotracheal stenosis is difficult. Congenital cases are rare and have a better prognosis than acquired ones. As with many disorders, the best treatment for 
pediatric laryngotracheal stenosis is prevention, and a thorough knowledge of tracheal anatomical dimensions is essential in this process [20].

Tracheal length has been studied with the help of different methods, with invasive and noninvasive techniques: chest radiography, computed tomography, magnetic resonance imaging, flexible bronchoscopy or cadaver dissection. Some of these studies have suggested that tracheal length may be related to patient's body height, sternum length and thyro-sternal length $[14,21,22]$.

This study aimed to analyze morphometric variables of the trachea in human fetuses and correlate them with fetal sex and age, in order to observe the growth of the trachea with respect to these variables.

\section{MATERIALS AND METHODS}

The study consisted of a descriptive anatomical design. Fifty-one human fetuses aged 20 to 38 weeks from both sexs, and kept fixed in 10\% formaldehyde solution were used. The fetuses, obtained in accordance with the Brazilian Law No. 8501 of 1992, which deals with the use of unclaimed corpses for use in studies and research, belong to the Anatomy Laboratory of Tiradentes University. The research was approved by the Tiradentes University Ethics Committee

(process No. 67749317.2.0000.5371).

The fetuses were separated into four groups (G) according to gestational age, which was obtained from the measurement of the crownrump length (CRL), with subsequent comparison with the fetal growth table [4] (Table 1).

Table 1: Selection of fetuses groups.

\begin{tabular}{|c|c|c|c|c|}
\hline \multirow{2}{*}{ Fetuses groups by age } & \multirow{2}{*}{$\begin{array}{c}\text { Number of } \\
\text { fetuses }\end{array}$} & \multicolumn{2}{|c|}{ Division by sex } & \multirow{2}{*}{ CRL } \\
\hline & & Female & Male & \\
\hline $20-24$ weeks (G1) & 10 & 6 & 4 & $15-23 \mathrm{~cm}$ \\
\hline $25-28$ weeks (G2) & 23 & 11 & 12 & $24-27 \mathrm{~cm}$ \\
\hline $29-32$ weeks (G3) & 10 & 4 & 6 & $28-30 \mathrm{~cm}$ \\
\hline $33-38$ weeks (G4) & 8 & 2 & 6 & $31-36 \mathrm{~cm}$ \\
\hline Total & 51 & 23 & 28 & \\
\hline
\end{tabular}

With the dissected tracheas, the following measurements were performed using a $0.01 \mathrm{~mm}$ precision digital caliper: total tracheal length (TL); pre-bifurcation length (PBL); bifurcation length (BL); proximal transverse external diameter (PTED); and distal transverse external diameter (DETED). The number of tracheal cartilage rings (NCR) was also counted by naked eye. These variables except the number of cartilaginous rings (NCR) were twice measured by two different researchers and values used in this study correspond to the average of the found values.

Figure 1 shows the morphometric reference points: TL corresponding to the sum of BL plus PBL; and PTED and DTED measured respectively the first and last trachea cartilage to its pre-split into right and left bronchi. The BL corresponded to the distance from the upper margin of the first cartilage that forms the carina to the lower bifurcation angle; $\mathrm{PBL}$ is the distance from the upper margin of the first tracheal cartilage to the lower margin of the last cartilage anterior to the carina.

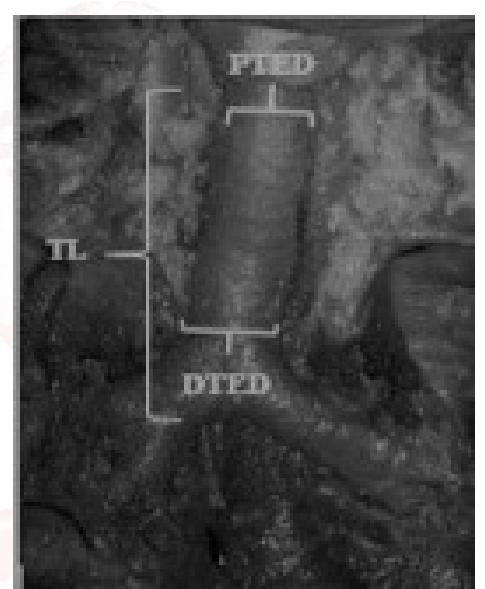

Fig. 1: Schematic representation of distances of tracheal morphometric variables. TL- Total length of the trachea; PTED - Proximal transverse external diameter; DTED Distal transverse external diameter.

Mean values and standard deviations were calculated for all age groups and sex. The Mann-Whitney tests were used for comparison in two groups, Kruskal-Wallis for three or more groups, Kruskal-Wallis-Bonferroni in multiple comparisons and bivariate ANOVA to assess the influence of sex, gestational age and both on measurements. The software used was R Core Team 2019 and the significance level adopted was $5 \%$.

\section{RESULTS}

Of the 51 fetus tracheas studied, 28 were of male fetuses and 23 of female ones. The fetal CRL ranged from 15 to $36 \mathrm{~cm}$ and were classified into groups, with the following quantities (n): $G 1 n=10 ; G 2 n=23 ; G 3 n=10$; and $\mathrm{G} 4 \mathrm{n}=8$. 
Table 2: Mean and standard deviation of morphometric data from human fetuses in relation to gender.

\begin{tabular}{|c|c|c|c|c|c|c|c|}
\hline & \multicolumn{6}{|c|}{ Gender } & \multirow[b]{3}{*}{ p-value } \\
\hline & \multicolumn{2}{|c|}{ Total } & \multicolumn{2}{|c|}{ Female } & \multicolumn{2}{|c|}{ Male } & \\
\hline & Mean & SD & Mean & SD & Mean & SD & \\
\hline TL & 33.85 & 7.72 & 33.93 & 8.16 & 33.78 & 7.48 & 0.902 \\
\hline PBL & 26.32 & 5.03 & 26.49 & 4.93 & 26.18 & 5.2 & 0.603 \\
\hline BL & 5.42 & 1.71 & 5.32 & 1.44 & 5.5 & 1.92 & 0.82 \\
\hline PTED & 5.65 & 0.83 & 5.56 & 0.8 & 5.72 & 0.87 & 0.399 \\
\hline DTED & 5.61 & 1.1 & 5.49 & 1.18 & 5.7 & 1.05 & 0.368 \\
\hline NCR & 16.28 & 2.26 & 15.88 & 2.32 & 16.57 & 2.23 & 0.608 \\
\hline
\end{tabular}

Table 2 shows the morphometric data related to TL, PBL, BL, PTED, DTED and NCR regarding gender. It can be observed that no statistically significant differences were found.

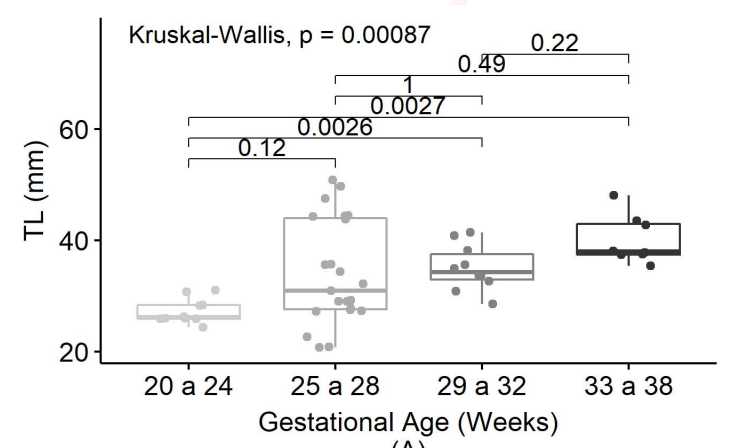

(A)

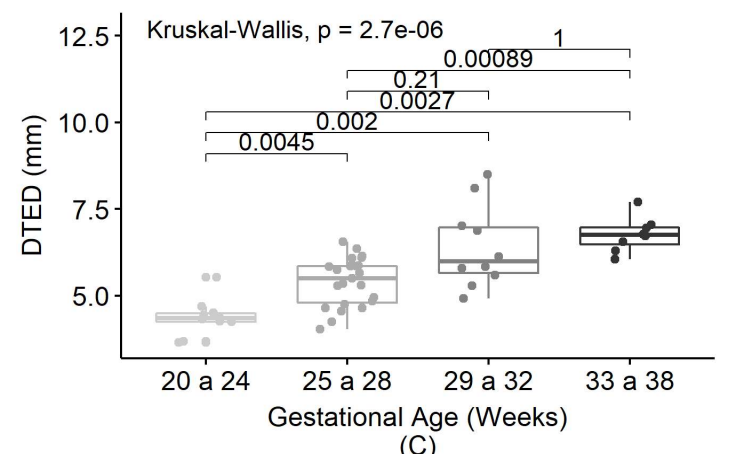

(C)

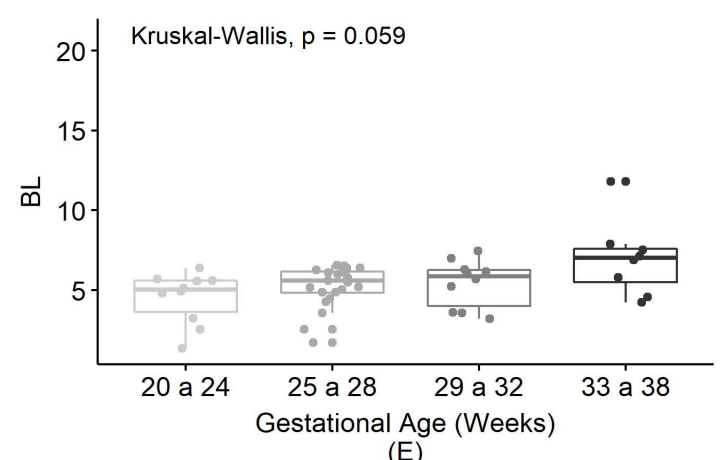

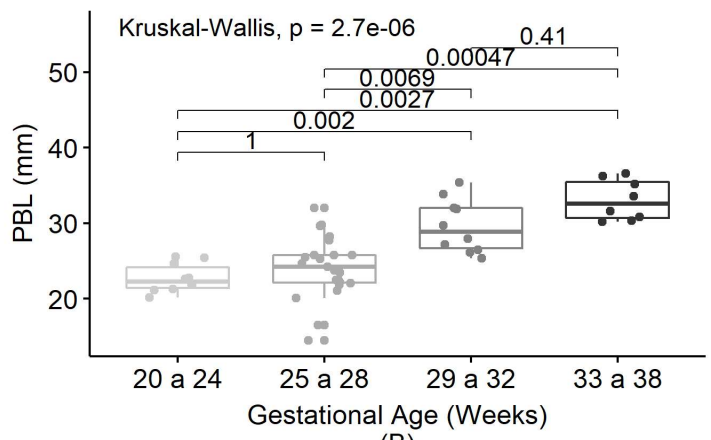

(B)

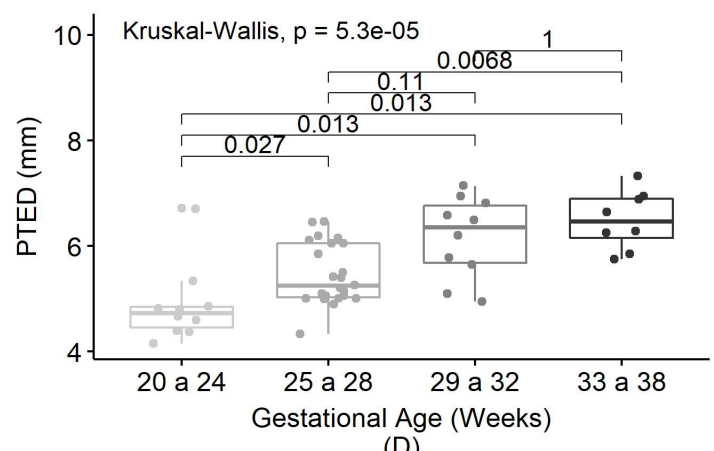

(D)

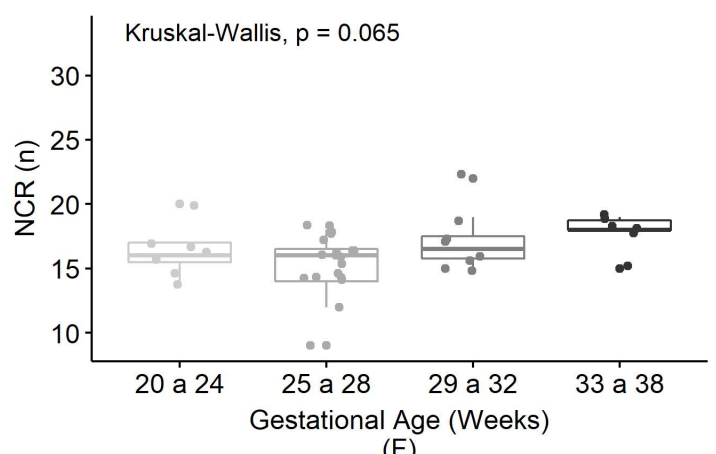

(F)

Fig. 2: Boxplot for gestational age and tracheal measurements.

Caption: SD - Standard Deviation; Mann-Whitney test; TLT - Total length of the trachea; PBL Pre-bifurcation length; BL - Bifurcation Length; PTED - Proximal transverse external diameter; DTED - Distal transverse external diameter; NCR - Number of cartilage rings.

The TL had progressive growth with the gestational age (GA) ( $p<0.001)$, where significant differences can be observed in the 20-24 week age group, 29-32 week age group $(p=0.002)$ and $33-38$ week age group $(p=0.003)$, Figure $2 a$.

Similarly, in $\mathrm{BL}$, significant differences in growth were also observed in the 20-24 week age group, 25-28 week age group, and 29-32 week age group $(p=0.002$ and $p=0.007)$ and $33-38$ week age group $(p=0.003$ and $p<0.001)$, Figure $2 b$. Regarding DTED (Figure 2c) and PTED (Fig. 2d) 
it was observed significant differences regarding the age groups from 20 to 24 weeks with the other age groups and 25 to 28 weeks with 33 to 38 weeks ( $p<0.05$ ). Significant differences regarding $B L$ and NCR were not observed. Figures $2 \mathrm{e}$ and $2 \mathrm{f}$, respectively.

In order to investigate the influence of dyad, GA and gender or both on tracheal measurements, a bivariate ANOVA was used. Thus, it was observed significant differences only for $G A$ in TLT, PBL, PTED and DTED measurements, finding no evidence for gender or both. BL measurements and NCR showed no evidence of difference with $\mathrm{GA}$, gender, or both (Table 3).

Table 3: GA and gender correlation in morphometric measures.

\begin{tabular}{cccc}
\hline & GA & Gender & GA* Gender \\
& $\mathbf{F}$ (p-value) & $\mathbf{F}$ (p-value) & $\mathbf{F}$ (p-value) \\
\hline TL & $4.659(0.007)$ & $0.413(0.524)$ & $0.101(0.959)$ \\
PBL & $18.75(<.001)$ & $1.929(0.172)$ & $0.549(0.652)$ \\
BL & $2.500(0.072)$ & $0.021(0.884)$ & $0.298(0.827)$ \\
PTED & $11.02(<.001)$ & $0.017(0.898)$ & $2.585(0.065)$ \\
DTED & $17.60(<.001)$ & $0.998(0.323)$ & $0.485(0.694)$ \\
NCR & $2.089(0.121)$ & $1.192(0.283)$ & $0.460(0.712)$ \\
\hline
\end{tabular}

Caption: F - Statistics F; ANOVA; SD - Standard Deviation; Mann-Whitney test; TL - Total length of the trachea; PBL - Pre-bifurcation length; BL - Bifurcation Length; PTED Proximal transverse external diameter; DTED - Distal transverse external diameter; NCR - Number of cartilage rings.

\section{DISCUSSION}

There are several techniques used in the literature to study the trachea: the traditional method of dissection, barometry, computed tomography radiographic study, with or without contrast, among others. In addition, there are also applications and programs that facilitate the study that may give more precision to the data obtained.

The present study on the tracheal anatomy was performed by dissecting fetuses fixed in formaldehyde solution. Fayoux et al (2006) [15] worked with new fetal larynges to ensure that airway dimensions were close to those of living patients. However, Daroszewski et al (2013) [8] reported that only $0.5-1.0 \%$ retraction occurred in fetal tracheas that were immersed in $10 \%$ neutral buffered formalin solution for 1 to 2 years. In turn, Szpinda et al (2012) [11] considered that the possible artifacts resulting from formalin fixation would probably be expressed in younger fetuses, because immature tracheas are mainly formed by loose connective tissue. The findings of this study, although they were obtained by dissecting fetal larynx fixed in formalin, and appear safe similar to experimental and anatomical findings of Fayoux et al (2006) [15] when they concluded that choosing the ideal endotracheal tube size in newborns would limit the risk of injury.

Regarding sex, it was not found significant difference between any of the studied parameters. This finding is reported from several authors $[3,5,11,12,16,23,24,25]$.

Harjeet et al (2008) [12] with the aid of a caliper carried tracheae dissected measures, which were radiographed after being injected with the solution of barium sulfate. The fetuses according to the crown-rump length (CRL) were separated into the groups that had the following measures: CRL $1=61-130 \mathrm{~mm}, \mathrm{CRL}$ $2=131-200 \mathrm{~mm}$ and $\mathrm{CRL} 3=201-270 \mathrm{~mm}$. The length of the trachea in CRL 1 ranged from 12.72 $\pm 2.50, \mathrm{CRL} 2=17.48 \pm 2.89$ and $\mathrm{CRL} 3=24.17$ \pm 2.30 ; The external circumference of the upper extremity ranged from $9.94 \pm 2.17$ in CRL $1,13.65$ \pm 1.42 in CRL 2 and $18.52 \pm 1.11$ in CRL 3 . In its turn, the external circumference proximal to the carina ranged from $9.94 \pm 1.85$ in CRL 1, 13.75 \pm 1.89 in CRL 2, and $18.53 \pm 0.89$ in CRL 3. The lengths used by these authors allow only the groups 2 and 3 of the present research could be compared, they were found in G2 TL $=34.06 \pm$ 9.28 and $35.01 \pm \mathrm{G} 3 \mathrm{TL}=4.13$. In turn, the PTED was in $\mathrm{G} 2=5.46 \pm 0.58$ and in $\mathrm{G} 3=6.17 \pm 0.77$, while the DTED in G2 $=5.4 \pm 0.7$ and G3 $=6.41$ \pm 1.19 , $(p<0.001)$. The findings found in other studies reported findings similar to those found in this study, ie, TL, PTED and DTED grow with $A G$, although the absolute values found in the study were lower.

Pre-bifurcation and bifurcation lengths, proximal transverse external diameters, and distal transverse transverse diameters followed a linear function, according to a study by Szpinda et al (2011) [11]. The absolute values found by Szpinda et al (2011) [11] are in agreement with the data found in this study. According to Szpinda et al (2012) [5], tracheal length values ranged from $10.37 \pm 2.15 \mathrm{~mm}$ for the 14-week fetus group and from $26.54 \pm 0.26 \mathrm{~mm}$ for the 25 -week 
age group $(p<0.0001)$. The present study was performed with fetuses from 20 weeks of age, and values of $27.27 \pm 2.22 \mathrm{~mm}$ were found for the group of fetuses from 20 to 24 weeks and $34.06 \pm 9.2 \mathrm{~mm}$ for fetuses 25 to 28 weeks old. Thus, the values of the current study seemed close to the values described by Szpinda et al (2012) [5] for fetuses within the same age range and with the same level of significance.

Tracheal length in humans has been investigated by only a few studies. Grillo $(1964,1999)[24,25]$ reported that adult human tracheas have an average length of $11.8 \mathrm{~cm}$ (range 10 to $13 \mathrm{~cm}$ ), with 18 to 22 cartilage rings. For Standring (2010) [1] the trachea would be 10 to $11 \mathrm{~cm}$ long and composed of 16 to 20 tracheal cartilages. Adamiec et al (2002) [3] stated that the number of tracheal rings varies from 6 to 20 , is constant and would not depend on gender $[3,16]$.

Cinar et al (2016) [16] counted the number of tracheal rings in the median sagittal plane. The trachea was measured between the lower margins of the cricoid cartilage for trachea bifurcation under two different conditions: relaxed and maximally stretched. These authors found that the number of cartilages ranged from $13.6 \pm 1.7$ for women and $13.3 \pm 1.6$ for men . Although this study was performed in adult cadavers, it did not entail any implication, since the total number of cartilages (16 to 20) is already established before birth $[2,16]$.

In the present study, the following NCR values were found: G1 $16.34 \pm 1.9 ;$ G2 $15.37 \pm 2.27$; G3 $17.13 \pm 2.36$; G4 17.83 \pm 1.47 , with $p=0.058$. It can be observed that the NCR did not follow a linear pattern, since $\mathrm{G} 2$ had values below $\mathrm{G} 1$. Thus, there was no statistically significant variation with the GA.

Gender had no significance in relation to any of the variables: total length of the trachea, the pre-bifurcation, the length of the bifurcation, the external transverse diameter proximal and distal cross had a related growth as gestational age increased. The number of tracheal cartilage was not related to gestational age.

\section{Conflicts of Interests: None}

\section{REFERENCES}

[1]. S. Standring, Gray's Anatomia: A base anatômica da prática clínica, 2010.
[2]. P. Tubino and E. Alves, Anatomia funcional da criança: bases morfológicas para a prática pediátrica clínica e cirúrgica. Editora Universidade de Brasilia, 2007.

[3]. E. Adamiec, E. Dziêcio ${ }^{3}$ owska-Baran, F. Czerwiñski, D. Miklaszewska, and I. Teul. Prenatal development of the human trachea. Folia Morphol. (Warsz)., 2002;61(2):123-125.

[4]. T. W. Sadler, Embriologia Médica, 11th ed. Rio de Janeiro: Langman, 2010.

[5]. M. Szpinda et al., New quantitative patterns of the growing trachea in human fetuses. Med. Sci. Monit., 2012;18(6):63-70.

https://doi.org/10.12659/MSM.882890

PMid:22648261 PMCid:PMC3560714

[6]. M. P. Wailoo and J. L. Emery. Normal growth and development of the trachea. Thorax, 1982;37(8):584587.

https://doi.org/10.1136/thx.37.8.584 PMid:7179187 PMCid:PMC459379

[7]. HARJEET, D. SAHNI, Y. K. BATRA, and S. RAJEEV. Anatomical dimensions of trachea, main bronchi, subcarinal and bronchial angles in fetuses measured ex vivo. Pediatr. Anesth., 2008;18(11):10291034.

https://doi.org/10.1111/j.1460-9592.2008.02775.x PMid:18950324

[8]. M. Daroszewski et al., Tracheo-bronchial angles in the human fetus - an anatomical, digital, and statistical study. Med. Sci. Monit. Basic Res., 2013;19:194-200.

https://doi.org/10.12659/MSMBR.889085

PMid:23857411 PMCid:PMC3724572

[9]. D. C. Helfer, J. Clivatti, A. M. Yamashita, and M. A. F. TSA. Anestesia para tratamento intraparto extraútero (EXIT) em fetos com diagnóstico pré-natal de malformações cervical e oral: Relato de casos. Rev Bras Anestesiol, 2012;62(3):411-423.

https://doi.org/10.1016/S0034-7094(12)70141-1

https://doi.org/10.1590/S0034-70942012000300013 PMid:22656686

[10]. P. M. S. Lassance et al., Procedimento Ex Utero e Intrapartum-EXIT-para correção de Malformação Congênita das Vias Aéreas e Pulmão-CPAM. Rev. Med. e Saúde Brasília, 2015;4(3).

[11]. M. Szpinda, M. Daroszewski, A. WoŸniak, A. Szpinda, and C. Mila-Kierzenkowska. Tracheal dimensions in human fetuses: An anatomical, digital and statistical study. Surg. Radiol. Anat., 2012;34(4):317323.

\section{https://doi.org/10.1007/s00276-011-0878-7} PMid:21984196 PMCid:PMC3334485

[12]. Harjeet, D. Sahni, Y. K. Batra, and S. Rajeev. Anatomical dimensions of trachea, main bronchi, subcarinal and bronchial angles in fetuses measured ex vivo. Paediatr. Anaesth., 2008;18(11):1029-1034. https://doi.org/10.1111/j.1460-9592.2008.02775.x PMid:18950324

[13]. T. Matsumoto and W. B. de Carvalho. Intubação traqueal. J. Pediatr. (Rio. J)., 2007;83(2):S83-S90. https://doi.org/10.1590/S0021-75572007000300010 
[14]. B. A. Khade, N. Yadav, and C. Divan. Morphometry of human trachea in male and female using computerized tomography-a comparative study. Indian J. Clin. Anat. Physiol., 2016;3(4):526. https://doi.org/10.5958/2394-2126.2016.00121.3

[15]. P. Fayoux, L. Devisme, O. Merrot, and B. Marciniak. Determination of Endotracheal Tube Size in a Perinatal PopulationAn Anatomical and Experimental Study. Anesthesiol. J. Am. Soc. Anesthesiol., 2006;104(5):954-960. https://doi.org/10.1097/ 00000542-200605000-00011 PMid:16645447

[16]. U. Cinar, S. Halezeroglu, E. Okur, M. A. Inanici, and S. Kayaoglu. Tracheal Length in Adult Human: The Results of 100 Autopsies. Int. J. Morphol., 2016;34(1):232-236. https://doi.org/10.4067/ S0717-95022016000100033

[17]. B. R. King, M. D. Baker, L. E. Braitman, J. Seidl-Friedman, and M. S. Schreiner. Endotracheal tube selection in children: a comparison of four methods. Ann. Emerg. Med., 1993;22(3):530-534.

https://doi.org/10.1016/S0196-0644(05)81937-7

[18]. D. B. Hawkins. Pathogenesis of subglottic stenosis from endotracheal intubation. Ann. Otol. Rhinol. Laryngol., 1987;96(1):116-117.

https://doi.org/10.1177/000348948709600126 PMid:3813374

[19]. J. C. Wain Jr. Postintubation tracheal stenosis. in Seminars in thoracic and cardiovascular surgery, 2009;21(3):284-289.

https://doi.org/10.1053/j.semtcvs.2009.08.001 PMid:19942129
[20]. P. Contencin, P. Narcy, and L. D. HOLINGER. Size of endotracheal tube and neonatal acquired subglottic stenosis. Arch. Otolaryngol. Neck Surg., 1993;119(8):815-819. https://doi.org/10.1001/ archotol.1993.01880200015002 PMid:8343241

[21]. C.-H. Cherng, C.-S. Wong, C.-H. Hsu, and S.-T. Ho. Airway length in adults: estimation of the optimal endotracheal tube length for orotracheal intubation. J. Clin. Anesth., 2002;14(4):271-274. https://doi.org/10.1016/S0952-8180(02)00355-0

[22]. C. C. P. Eagle. The relationship between a person's height and appropriate endotracheal tube length. Anaesth. Intensive Care, 1992;20(2):156-160. https://doi.org/10.1177/0310057X9202000206 PMid:1595848

[23]. M. Szpinda et al., The normal growth of the tracheal wall in human foetuses. Arch. Med. Sci., 2013;9(5):922-929. https://doi.org/10.5114/aoms.2012.31411 PMid:24273580 PMCid:PMC3832814

[24]. H. C. Grillo, E. F. Dignan, T. Miura, and J. G. Scannell. Extensive resection and reconstruction of mediastinal trachea without prosthesis or graft: an anatomical study in man. J. Thorac. Cardiovasc. Surg., 1964;48(5):741-749. https://doi.org/10.1016/S0022-5223(19)33357-4

[25]. H. C. Grillo. Surgical Anatomy of the Trachea and Techniques of Resection. Gen. Thorac. Surg., 1999;873-883.

How to cite this article:

Catarine C. Matos, Rodrigo R. Almeida, José A. Aragão, Erasmo Almeida-Junior, Francisco P. Reis. MORPHOMETRIC STUDY OF THE TRACHEA IN HUMAN FETUSES. Int J Anat Res 2020;8(3.3):7738-7744. DOI: $10.16965 /$ ijar.2020.205 